\title{
A hybrid fluoride layered perovskite, $\left(\mathrm{enH}_{2}\right) \mathrm{MnF}_{4}$
}

Teng Li ${ }^{a}$, Rebecca Clulow ${ }^{a}$, Alasdair J. Bradford ${ }^{a}, b$, Stephen L. Lee ${ }^{b}$, Alexandra M. Z. Slawin ${ }^{a}$ and Philip Lightfoot*a

a. School of Chemistry and EaStChem, University of St Andrews, St Andrews, Fife, KY16 9ST, UK. e-mail: pl@st-andrews.ac.uk

b. School of Physics, University of St Andrews, St Andrews, Fife, KY16 9SS, UK

\section{Supplementary Information}

\section{Synthesis}

$0.093 \mathrm{~g}(1 \mathrm{mmol})$ manganese(II) fluoride $\left(\mathrm{MnF}_{2}\right), 0.54 \mathrm{~mL}$ (8 mmol) ethylenediamine $\left(\mathrm{C}_{2} \mathrm{H}_{6} \mathrm{~N}_{2}\right)$ and 0.4 $\mathrm{mL}$ (11.2 mmol) 48\% 51\% hydrofluoric acid (HF) were dissolved in $2 \mathrm{~mL} \mathrm{H}_{2} \mathrm{O}$ at room temperature. A homogeneous mixture with an overall molar composition of $1 \mathrm{MnF}_{2}: 8 \mathrm{C}_{2} \mathrm{H}_{6} \mathrm{~N}_{2}: 11.2 \mathrm{HF}: 111.1 \mathrm{H}_{2} \mathrm{O}$ was formed, which was sealed in a $30 \mathrm{~mL}$ Teflon-lined stainless-steel autoclave and then was placed in a $190{ }^{\circ} \mathrm{C}$ oven and maintained for 48 hours. After the autoclave was cooled to room temperature, colourless single crystals were obtained by filtration.

We also synthesised a $\mathrm{Ni}$ analogue, which appears to be isostructural with the title compound, but contains a minor impurity phase (Fig. S6). $\left.0.097 \mathrm{~g} \mathrm{(1} \mathrm{mmol)} \mathrm{nickel(II)} \mathrm{fluoride} \mathrm{(} \mathrm{NiF}_{2}\right), 0.135 \mathrm{~mL}$ (2 mmol) ethylenediamine $\left(\mathrm{C}_{2} \mathrm{H}_{6} \mathrm{~N}_{2}\right)$ and $0.6 \mathrm{~mL}(16.8 \mathrm{mmol}) 48 \% \sim 51 \%$ hydrofluoric acid $(\mathrm{HF})$ were dissolved in $2 \mathrm{~mL} \mathrm{H}_{2} \mathrm{O}$ at room temperature. A homogeneous mixture with an overall molar composition of $1 \mathrm{NiF}_{2}$ : $2 \mathrm{C}_{2} \mathrm{H}_{6} \mathrm{~N}_{2}: 16.8 \mathrm{HF}: 111.1 \mathrm{H}_{2} \mathrm{O}$ was formed, which was sealed in a $30 \mathrm{~mL}$ Teflon-lined stainless-steel autoclave and then was placed in a $190^{\circ} \mathrm{C}$ oven and maintained for 48 hours. After the autoclave was cooled to room temperature, colourless single crystals were obtained by filtration. Elemental analysis: (Anal. Calc. (\%) for $\mathrm{C}_{2} \mathrm{H}_{10} \mathrm{~F}_{4} \mathrm{NiN}_{2}$ : C, 12.20; $\mathrm{H}, 5.12 ; \mathrm{N}, 14.23$. Found: $\mathrm{C}, 12.49 ; \mathrm{H}, 4.17 ; \mathrm{N}, 14.11$ ).

\section{Single Crystal XRD}

Single crystal data at $93 \mathrm{~K}$ were collected on a Rigaku XtaLAB P200 diffractometer using multi-layer mirror monochromated Mo- $\mathrm{K}_{\alpha}$ radiation. Two further crystals were measured at $173 \mathrm{~K}$ and $295 \mathrm{~K}$, on a Rigaku SCX Mini diffractometer using Mo- $K_{\alpha}$ radiation. Both of these crystals were found to be twinned, but good quality refinements were achieved using the TWINROTMAT algorithm in the PLATON suite, ${ }^{1}$ via the twin matrices shown below.

$$
\left(\begin{array}{ccc}
-1 & 0 & 0 \\
0 & -1 & 0 \\
-0.002 & 0 & 1
\end{array}\right) \text { and }\left(\begin{array}{ccc}
-1 & 0 & 0 \\
0 & -1 & 0 \\
0.005 & 0 & 1
\end{array}\right)
$$

Data were collected and processed using CrystalClear (Rigaku). ${ }^{2}$ Structures were solved by direct methods and refined using SHELX-2014 ${ }^{3}$ incorporated in the WinGX program. ${ }^{4}$ Absorption corrections 
were performed semi-empirically from equivalent reflections on the basis of multi-scans. All non-H atoms were refined anisotropically and hydrogen atoms were treated as riding atoms.

\section{Magnetic Characterisation}

The magnetic measurements were made using a Quantum Design (MPMS XL) SQUID magnetometer. All measurements presented were made by cooling a known mass of material in an applied magnetic field of 100 Oe between room temperature $(\sim 300 \mathrm{~K})$ and $2 \mathrm{~K}$. The magnetometer measures the magnetic moment $\mu$ of the sample in $e m u$, from which the dimensionless susceptibility is defined by $\chi=\mu / V H$. This has been used to calculate the molar susceptibility presented in the figures.

Table S1 Crystallographic data and refinement details

\begin{tabular}{|c|c|c|c|}
\hline Temperature & $93 \mathrm{~K}$ & $173 \mathrm{~K}$ & $298 K$ \\
\hline Formula & $\left(\mathrm{C}_{2} \mathrm{H}_{10} \mathrm{~N}_{2}\right) \mathrm{MnF}_{4}$ & $\left(\mathrm{C}_{2} \mathrm{H}_{10} \mathrm{~N}_{2}\right) \mathrm{MnF}_{4}$ & $\left(\mathrm{C}_{2} \mathrm{H}_{10} \mathrm{~N}_{2}\right) \mathrm{MnF}_{4}$ \\
\hline Formula weight & 193.06 & 193.06 & 193.06 \\
\hline Crystal system & Monoclinic & Monoclinic & Monoclinic \\
\hline Space group & $P 2_{1} / c$ & $P 2_{1} / c$ & $P 2_{1} / c$ \\
\hline$a / \AA ̊$ & $8.1735(18)$ & $8.1634(7)$ & $8.1632(7)$ \\
\hline b/Å & $5.9868(13)$ & $5.9917(5)$ & $6.0028(5)$ \\
\hline$c / \AA ̊$ & $5.9637(14)$ & $5.9622(5)$ & $5.9759(5)$ \\
\hline $6 /^{\circ}$ & $90.287(6)$ & $89.937(11)$ & $90.183(13)$ \\
\hline$V / \AA^{3}$ & $291.82(11)$ & $291.63(4)$ & $292.83(4)$ \\
\hline$z$ & 2 & 2 & 2 \\
\hline Measured ref & 3454 & 2735 & 2786 \\
\hline Independent ref & $\begin{array}{l}526 \\
{[R(\text { int })=0.027]}\end{array}$ & $\begin{array}{l}653 \\
{[R(\text { int })=0.049]}\end{array}$ & $\begin{array}{l}666 \\
{[R(\mathrm{int})=0.082]}\end{array}$ \\
\hline GOOF & 1.123 & 0.995 & 1.048 \\
\hline $\begin{array}{l}\text { Final } R \text { indices } \\
(I>2 \sigma(I))\end{array}$ & $R_{1}=0.0141$ & $R_{1}=0.0202$ & $R_{1}=0.0338$ \\
\hline
\end{tabular}

Table S2 Selected bond lengths $(\AA \AA)$ and bond angles $\left({ }^{\circ}\right)$ versus temperature

\begin{tabular}{llll}
\hline & $\mathbf{9 3 ~ K}$ & $\mathbf{1 7 3 ~ K}$ & $\mathbf{2 9 8} \mathbf{K}$ \\
\hline Mn-F2 & $2.1030(8)$ & $2.0991(11)$ & $2.100(2)$ \\
Mn-F1 & $2.1449(6)$ & $2.1426(9)$ & $2.1462(18)$ \\
Mn-F1 & $2.1458(6)$ & $2.1480(9)$ & $2.1510(17)$ \\
Mn-F-Mn & $159.94(4)$ & $160.15(5)$ & $160.50(11)$ \\
N1-(H)---F1 & $2.7652(14)$ & $2.757(2)$ & $2.765(4)$ \\
N1-(H)---F2 & $2.6795(13)$ & $2.6828(16)$ & $2.687(3)$ \\
N1-(H)---F2 & $2.7408(16)$ & $2.741(4)$ & $2.750(7)$ \\
N1-H-F1 angle & 177.8 & 177.9 & 177.6 \\
N1-H-F2 angle & 173.2 & 173.0 & 173.5 \\
N1-H-F2 angle & 157.8 & 157.6 & 157.0 \\
\hline
\end{tabular}



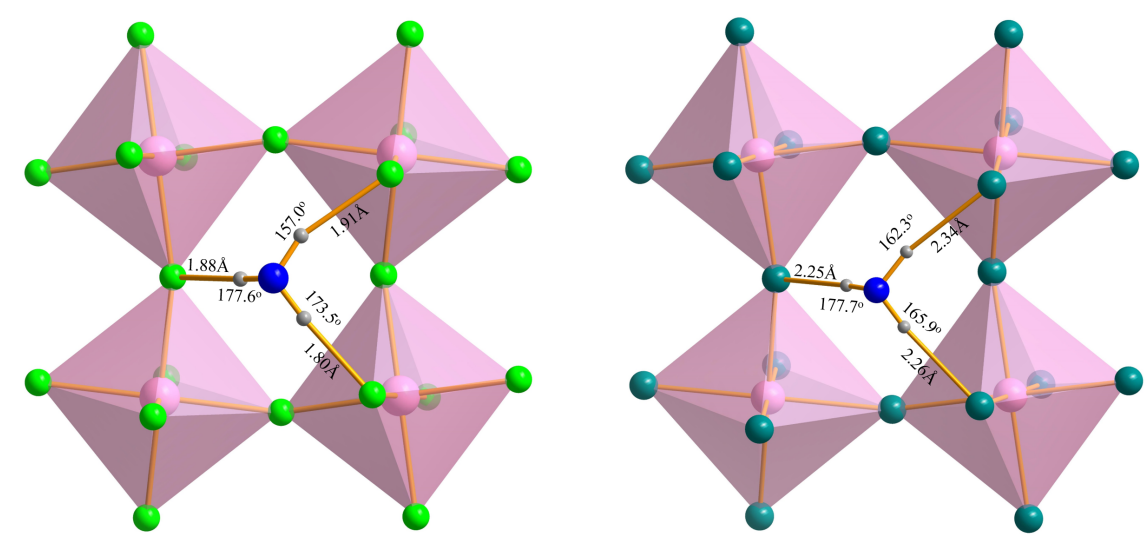

Figure $\mathrm{S1} \mathrm{H}$-bonding in $\left(e n \mathrm{H}_{2}\right) \mathrm{MnF}_{4}$ (left) and $\left(\mathrm{enH}_{2}\right) \mathrm{MnCl}_{4}$ (right) at ambient temperature. ${ }^{5}$

\section{Powder XRD}

Powder X-ray diffraction (PXRD) data were collected on a Panalytical Empyrean diffractometer, in reflection geometry, using $\mathrm{CuK}_{\alpha 1}$ radiation. Rietveld refinement was carried out using the GSAS package $^{6}$ with the EXPGUI interface. ${ }^{7}$ The main point of the PXRD refinement was to establish the degree of phase purity; hence fixed crystallographic models were used, based on the single refinement at $295 \mathrm{~K}$, with only profile and lattice parameters being refined. A distinct preferred orientation was observed, with (h00) reflections exhibiting artificially high intensity due to 'platy' crystal geometry (Fig. S2); these reflections were excluded from the refinement (Fig. S3). A significant peak from the sample holder is also present (Fig. S4). The fraction of $\mathrm{MnF}_{2}$ impurity was determined to be $1.2(1) \%$ by weight, which supports the purity of the sample, based on elemental analysis. A second batch (with somewhat higher impurity content, 9\%,) was run on a Panalytical Empyrean diffractometer, in transmission (capillary) geometry, using $\mathrm{MoK}_{\alpha}$ radiation: this shows (Fig. S5) that the preferred orientation can be minimised in this geometry, and also supports the much smaller amount of impurity present in the original sample, used for magnetic analysis. 


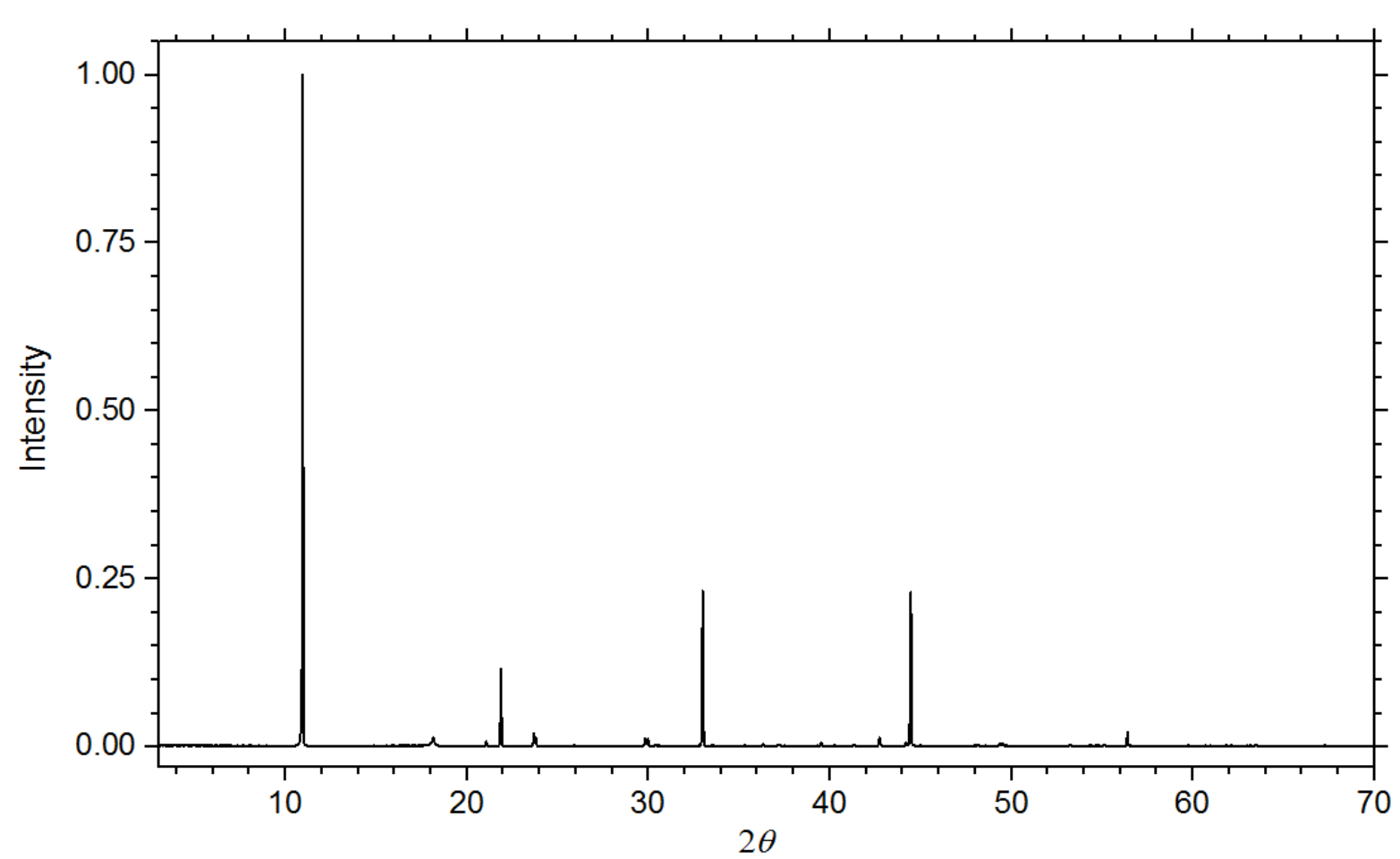

Figure S2. Raw PXRD data $\left(\mathrm{CuK}_{1}\right.$, at $\left.25^{\circ} \mathrm{C}\right)$ for $\left(\mathrm{enH}_{2}\right) \mathrm{MnF}_{4}$, illustrating the extreme preferred orientation effect (h00 reflections).

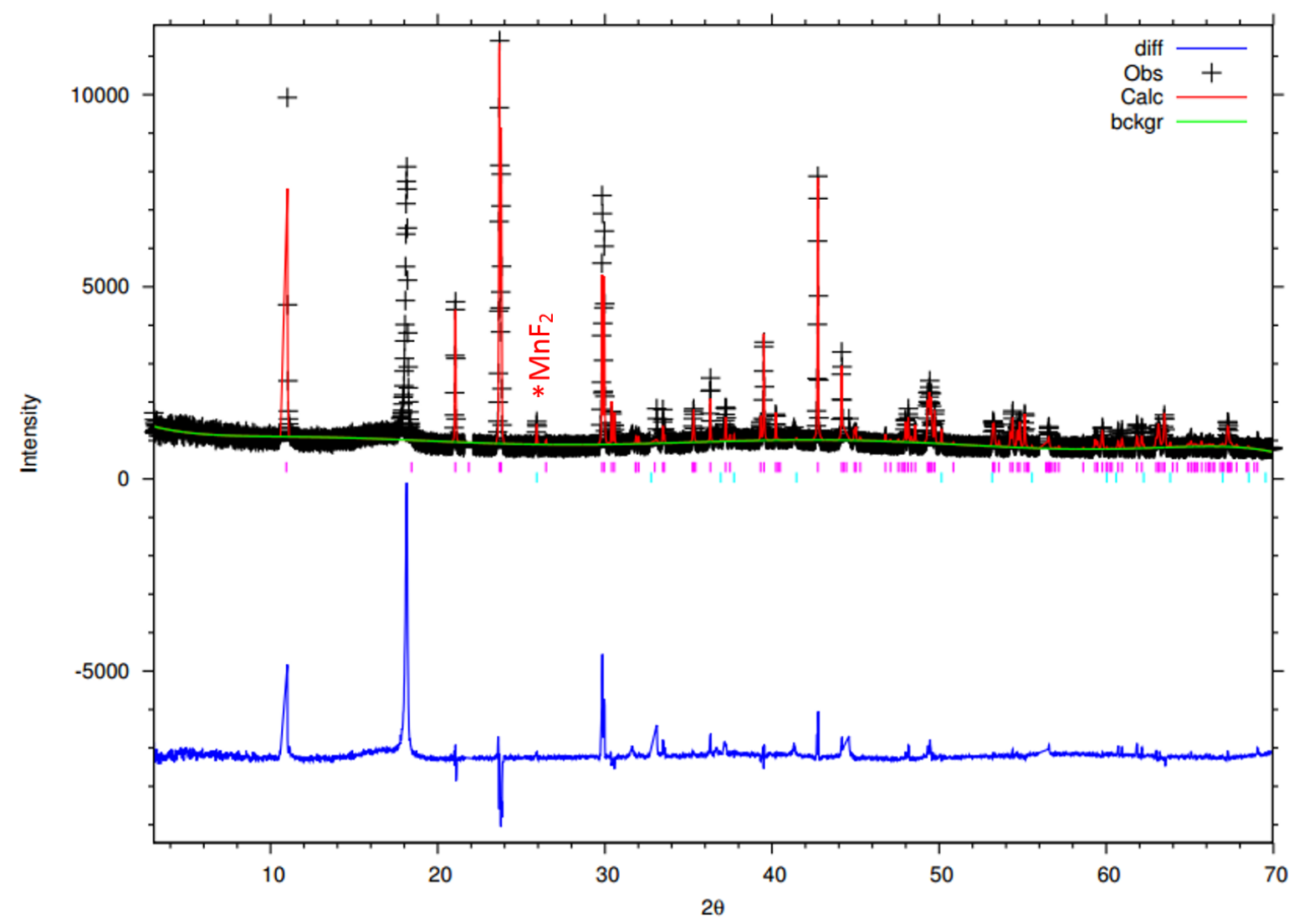

Figure S3. Rietveld plot (PXRD, CuK $\alpha_{1}$, at $\left.25^{\circ} \mathrm{C}\right)$ for $\left(e n \mathrm{H}_{2}\right) \mathrm{MnF}_{4}$. Dominant h00 reflections have been excluded. The peak near $2 \theta \sim 18^{\circ}$ is due to the sample holder (see Fig. S4). The most significant peak of the $\mathrm{MnF}_{2}$ impurity ( $\left.1 \%\right)$ is highlighted. 


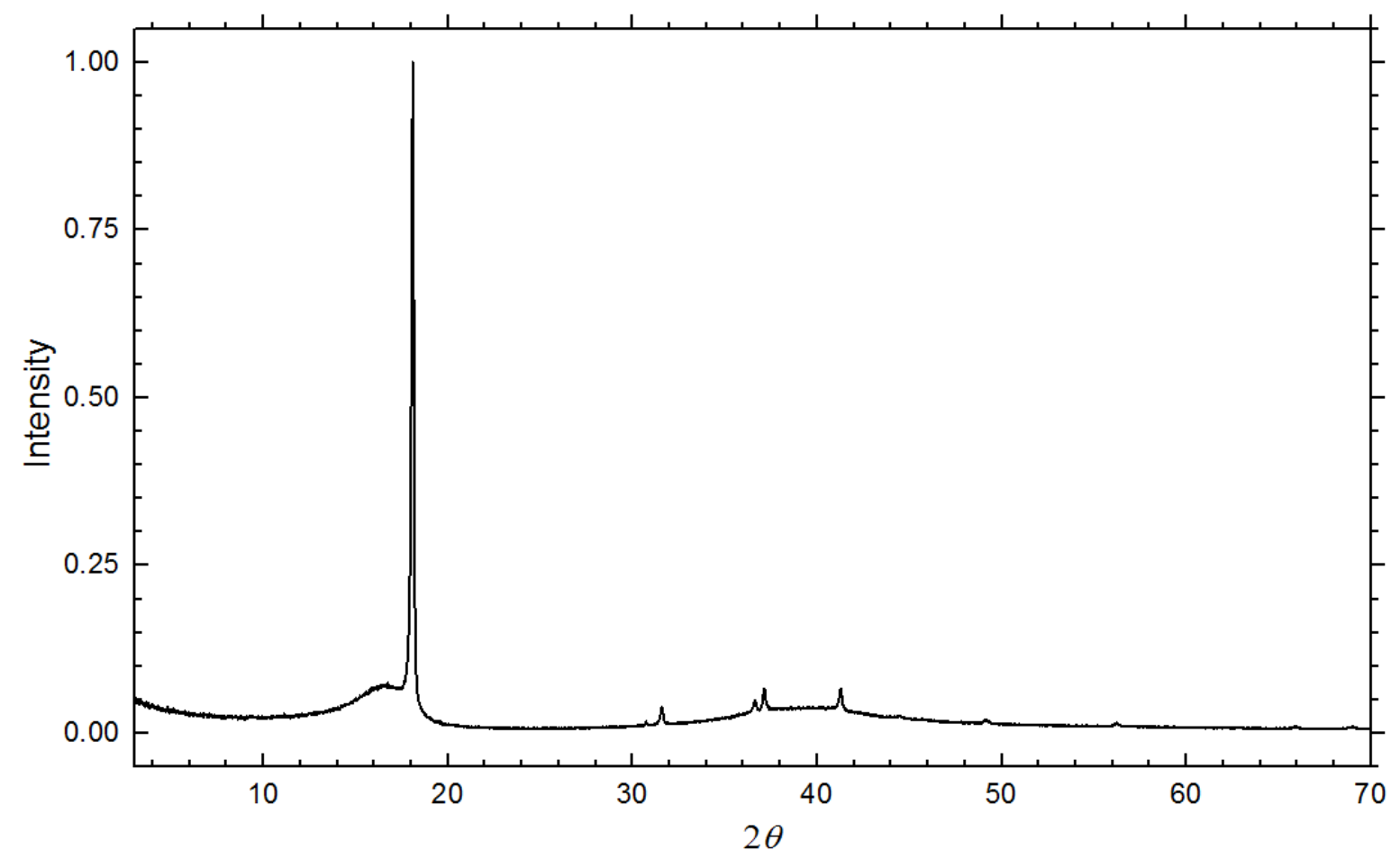

Figure S4. PXRD (CuK $\left.\alpha_{1}\right)$ for the teflon sample holder (see Fig. S3)

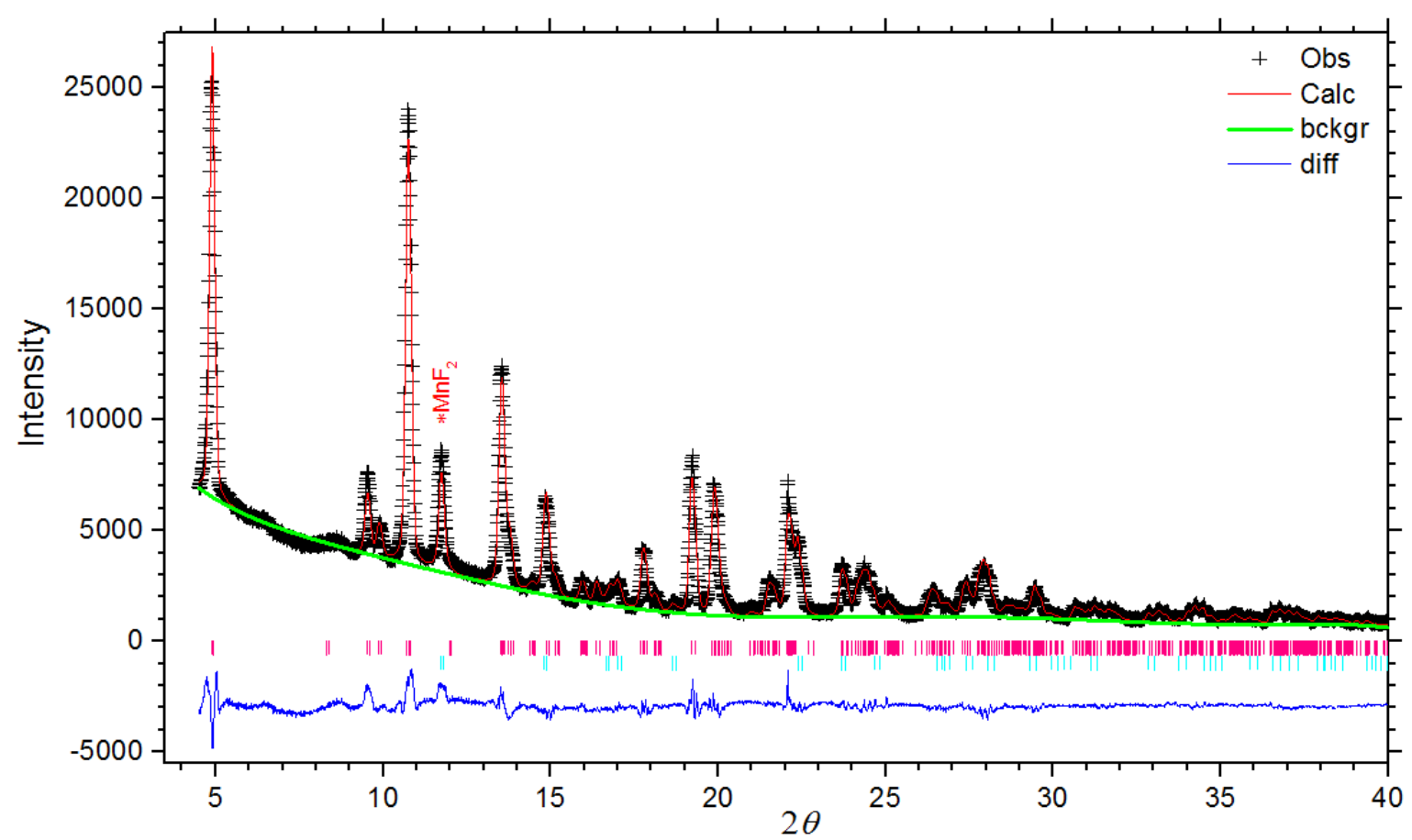

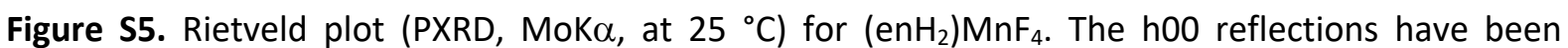
included, revealing the lack of preferred orientation in capillary mode. The most significant peak of the $\mathrm{MnF}_{2}$ impurity ( 9\%) is highlighted. 


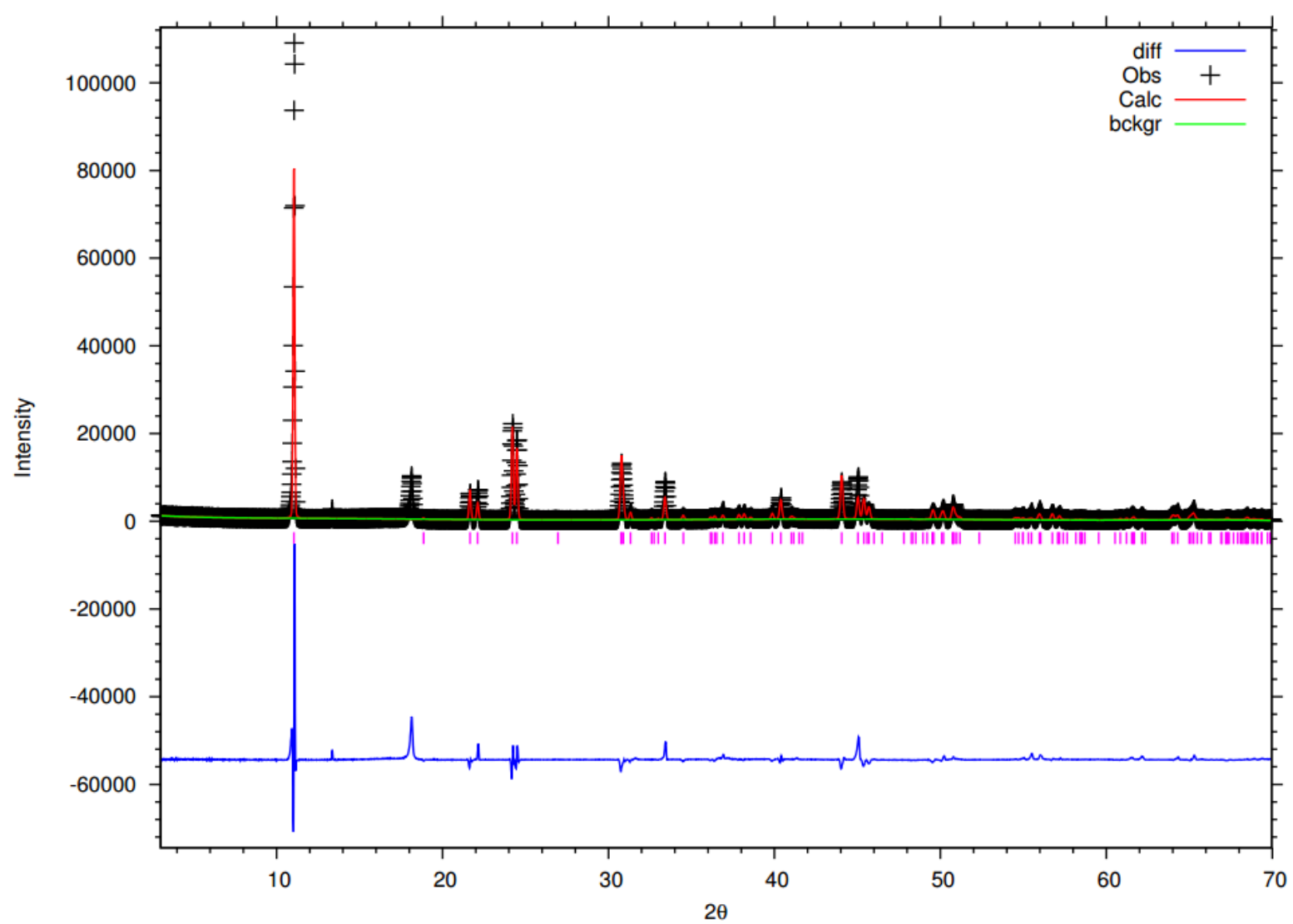

Figure S6. Rietveld plot (PXRD at $25{ }^{\circ} \mathrm{C}$ ) for $\left(\mathrm{enH}_{2}\right) \mathrm{NiF}_{4}$. The peak near $2 \theta \sim 13.3^{\circ}$ is due to an unidentified minor impurity; the peak near $2 \theta \sim 18^{\circ}$ is due to the sample holder. Refined lattice parameters, based on the $\left(\mathrm{enH}_{2}\right) \mathrm{MnF}_{4}$ model, $a=8.0602(6) \AA, b=5.8233(5) \AA, c=5.8152(5) \AA$, $\beta=$ $91.077(6)^{\circ}$.

\section{Symmetry Mode Analysis}

The on-line tool ISODISTORT was used to determine the active modes in $\left(\mathrm{enH}_{2}\right) \mathrm{MnF}_{4}$. The output for the $93 \mathrm{~K}$ dataset is provided in the supplementary file 'Isodistort analysis'. Changes in mode amplitudes at lower temperatures are minor, as suggested by the bonding data provided in Table S2.

In addition, ISODISTORT was used to identify all possible models based on the combinations of the three tilt modes, $\mathrm{M}_{3}{ }^{+}, \mathrm{M}_{5}{ }^{+}$and $\mathrm{X}_{3}{ }^{+}$(i.e those listed in Table 1 of the manuscript). These are also provided in the file 'Isodistort analysis'.

\section{References}

1 A. L. Spek, Acta Crystallogr. Sect. D Biol. Crystallogr., 2009, 65, 148-155.

2 Rigaku (2014). CrystalClear. Rigaku Corporation, Tokyo, Japan

3 G. M. Sheldrick, Acta Crystallogr. Sect. C Struct. Chem., 2015, 71, 3-8.

4 L. J. Farrugia, J. Appl. Crystallogr., 2012, 45, 849-854.

5 K. Tichy, J. Benes and W. Halg, Acta Crystallogr. Sect. B, 1978, 34, 2970-2981. 
6 A. C. Larson and R. B. Von Dreele, General Structure Analysis System (GSAS), 2004.

7 B. H. Toby, J. Appl. Crystallogr., 2001, 34, 210-213. 